\title{
Tamanho de amostra para experimentos com feijão-de-vagem em diferentes ambientes
}

\author{
Sample size for experiments with bean pods in different environments
}

\author{
Fernando Machado Haesbaert ${ }^{I}$ Daniel Santos ${ }^{I}$ Alessandro Dal'Col Lúcio ${ }^{\text {II* }}$ \\ Vilson Benz ${ }^{\text {III }}$ Bruno Ioppi Antonello ${ }^{I}$ Ana Lúcia de Paula Ribeiro ${ }^{\text {IV }}$
}

\section{RESUMO}

\begin{abstract}
Com o objetivo de estimar o tamanho de amostra para a fitomassa fresca de vagens de feijão-de-vagem, foram realizados cinco experimentos em branco com a cultivar 'Macarrão' no outono/inverno de 2009 e na primavera/verão de 2010, em estufa, túnel e a campo. As unidades básicas (UB) foram duplas de plantas, resultando em $36 U B$ por linha de cultivo, na estufa, e de $42 U B$ no túnel e a campo. Para cada linha de cultivo em cada colheita e agrupamento de colheitas, estimou-se a média, a variância e o coeficiente de variação (CV\%). Quando as variâncias das linhas não foram heterogêneas, utilizou-se, para o cálculo do tamanho de amostra, o $\mathrm{CV} \%$ do experimento, quando foram heterogêneas, utilizou-se o CV\% da linha em que este foi maior. Foi possivel concluir que a variabilidade produtiva da fitomassa fresca de vagens aumenta em condições meteorológicas adversas e que analisar a produção total possibilita a utilização de menores tamanhos de amostra. Nessa condição, para uma semiamplitude do intervalo de confiança da média (D\%) de 10 no outono/inverno, é necessário amostrar, na linha de cultivo, 28 plantas na estufa, 21 no túnel e 26 no campo. Na primaveral verão, para um $D \%=10$, é necessário amostrar, na linha de cultivo, 22 plantas em cultivos em túnel e 24 a campo.
\end{abstract}

Palavras-chave: amostragem, Phaseolus vulgaris, ambiente protegido, precisão experimental.

\section{ABSTRACT}

Aiming to estimate the sample size for the fresh weight of pods of bean pod, five experiments were performed with blank Macarrão at autumn / winter 2009 and spring / summer 2010, in greenhouse, tunnel and field. The basic units $(B U)$ were pairs of plants, resulting in 36 per line of $U B$ cultivation in the greenhouse, and $42 B U$ in tunnel and field. For each row of plants in each harvest and group of crops it was estimated the mean, variance and coefficient of variation (CV\%). When the variances were not heterogeneous lines, it was used for calculation the of the sample size, the CV\% of the experiment, when they were heterogeneous, it was used the $\mathrm{CV} \%$ of the line in which this was higher. It was concluded that the variability of production of fresh pods increases in adverse weather conditions. The analysis of total production enables the use of smaller sample sizes. In this condition, for a semiamplitude of the mean confidence interval (D\%) of 10 in fall / winter, it is necessary to sample in the row of plants, 28 plants in the greenhouse, 21 in the tunnel and 26 on the field. In the spring / summer for a $D=10 \%$, it was necessary to sample in the row of plants, 22 plants in tunnel cultivation and 24 on the field.

Key words: sampling, Phaseolus vulgaris L., protected environment, experimental precision.

\section{INTRODUÇÃO}

O feijão-de-vagem (Phaseolus vulgaris L.) pode ser caracterizado como uma hortaliça cujo grupo de variedades, adaptado à produção e ao consumo, tem importância mundial (FILGUEIRA, 2000). Ele constitui fonte de fibra, com apreciável quantidade de vitaminas B1 e B2, além de possuir, em pequenas quantidades, flúor, potássio, cálcio, ferro e vitaminas, além de proteínas (MALUF et al., 2002). Difere-se do feijão comum, porque suas vagens são colhidas ainda

${ }^{\mathrm{I} C u r s o ~ d e ~ A g r o n o m i a, ~ U n i v e r s i d a d e ~ F e d e r a l ~ d e ~ S a n t a ~ M a r i a ~(U F S M), ~ S a n t a ~ M a r i a, ~ R S, ~ B r a s i l . ~}$

IIDepartamento de Fitotecnia, Centro de Ciências Rurais (CCR), UFSM, 97105-900, Santa Maria, RS, Brasil. E-mail: adlucio@smail.ufsm.br.*Autor para correspondência.

IIIPrograma de Pós-graduação em Agronomia, CCR, UFSM, Santa Maria, RS, Brasil.

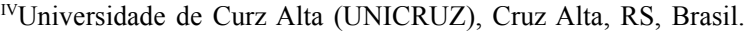


imaturas. Nesse estágio, elas são utilizadas na alimentação de várias formas, podendo ser industrializadas ou consumidas in natura.

Algumas pesquisas, como as de ABREU et al. (2004) e HELDWEIN et al. (2010), já vêm sendo realizadas com essa cultura, tanto em ambiente protegido como em ambiente natural, visando ao melhor conhecimento da cultura e aumento da produtividade. Como o consumo da vagem vem aumentando nos últimos anos, cada vez mais pesquisas deverão ser realizadas com essa cultura e é muito importante que sejam realizadas determinações que diminuam os custos e propiciem mais rapidez a essas pesquisas.

A técnica de amostragem proporciona várias vantagens. Dentre elas, menor custo e rapidez na obtenção e na análise dos dados. Além disso, os pesquisadores podem ser selecionados, treinados e supervisionados de forma mais cuidadosa (MUNIZ \& ABREU, 1999). Quando se trabalha com amostragem, a determinação de um tamanho de amostra ajustado às características da população passa a ser um importante passo no planejamento da pesquisa. FERNANDES \& SILVA (1996) salientam que quanto maior for o tamanho da amostra, maior é a precisão e, em consequência disso, o coeficiente de variação amostral tende a diminuir, pois um aumento no tamanho da amostra reduz a variância da média amostral. Porém, maiores serão os gastos e o tempo para realização da amostragem. Por outro lado, amostras pequenas podem resultar em redução da precisão dos experimentos.

Alguns estudos vêm sendo realizados para estimar o tamanho de amostra para culturas olerícolas cultivadas em ambiente protegido. No entanto, para a cultura do feijão-de-vagem, não se encontra nenhum relato na literatura. Trabalhando com pimentão em estufa plástica, LÚCIO et al. (2003) determinaram que amostras de 56 e 50 plantas por fileira em cada colheita, para as estações sazonais inverno-primavera e verãooutono, respectivamente, são suficientes para uma confiança de $95 \%$. SOUZA et al. (2002) concluíram que o tamanho de amostra para o peso da massa de frutos de abóbora italiana deve ser de 24 e 21 plantas por fileira em cada colheita, respectivamente para as estações sazonais verão/outono e inverno/primavera, para uma semi-amplitude do intervalo de confiança de $10 \%$ e em nível de $5 \%$ de probabilidade de erro. Para a cultura da alface, MARODIN et al. (2000) apresentaram, como tamanho de amostra para fitomassa fresca de alface hidropônica, o valor de 40 plantas, considerando uma semi-amplitude do intervalo de confiança $(\mathrm{D} \%) \mathrm{de}$ $5 \%$ e de sete plantas para $\mathrm{D} \%=20 \%$. Também trabalhando com alface, SANTOS et al. (2007) recomendam que devam ser amostradas três plantas por perfil hidropônico com frequência de três em três dias, para ajustes de curvas de crescimento, considerando a fitomassa seca total da planta..

O objetivo deste trabalho foi estimar o tamanho de amostra para a fitomassa fresca de vagens de feijão-de-vagem em experimentos em estufa, túnel e a campo, e verificar o comportamento do tamanho de amostra para análise da produção de vagens de maneira fracionada.

\section{MATERIAL E MÉTODOS}

Os experimentos em branco foram realizados na área experimental do Departamento de Fitotecnia no Campus da Universidade Federal de Santa Maria, no município de Santa Maria-RS, latitude 2942’23'S, longitude $53^{\circ} 43^{\prime} 15^{\prime}$ 'W e altitude de $95 \mathrm{~m}$. O clima da região, segundo a classificação de Köeppen (MORENO, 1961), é do tipo Cfa - temperado chuvoso, com chuvas bem distribuídas ao longo do ano e subtropical do ponto de vista térmico. O solo é classificado no Sistema Brasileiro de Classificação de Solos (EMBRAPA, 1999) como Argissolo Vermelho Distrófico arênico.

Os cultivos foram realizados no outonoinverno (23/03/09 a 03/07/09) e na primavera-verão (09/ 10/09 a 06/01/10). No outono/inverno os experimentos foram realizados em uma estufa plástica, em um túnel alto e a campo. Na primavera/verão, foram realizados em um túnel alto e a campo. A estufa possui estrutura metálica do tipo arco pampeano, pé direito de $2 \mathrm{~m}$ e $3,5 \mathrm{~m}$ na parte central, com $20 \mathrm{~m}$ de comprimento e $10 \mathrm{~m}$ de largura, orientada no sentido norte-sul. O túnel possui pé direito de $3 \mathrm{~m}$, 20m de comprimento e também orientação norte-sul. A cobertura dos ambientes protegidos foi feita com um filme de polietileno de baixa densidade (PEBD), com espessura de 100 micras e aditivo anti-UV. A área utilizada para o cultivo a campo e em túnel na primeira época de cultivo, foi a mesma utilizada na segunda época.

Em ambos os experimentos, foram utilizados camalhões com aproximadamente $0,20 \mathrm{~m}$ de altura e 0,40m de largura, cobertos com faixas de mulching de filme opaco de PEBD de cor preta. Na estufa, foram seis camalhões no túnel e a campo foram três. A irrigaçao foi realizada através de um sistema de gotejamento.

A cultivar foi a 'Macarrão' de crescimento indeterminado. Foram utilizadas, na estufa, 72 plantas por camalhão (linha de cultivo) e 84 no túnel e a campo. O espaçamento foi de $0,2 \mathrm{~m}$ entre plantas e de $1 \mathrm{~m}$ entre linhas. Desde o início de seu crescimento, as plantas foram tutoradas verticalmente com o uso de fios de ráfia, os quais foram amarrados em dois arames que estavam dispostos ao longo do camalhão.

Ciência Rural, v.41, n.1, jan, 2011. 
As plantas foram agrupadas em duplas, e construíram as unidades básicas (UB), resultando em 36UB por linha de cultivo, na estufa, e de 42UB no túnel e a campo. A colheita das vagens de cada dupla de planta foi realizada em 23/05/09 (colheita 1), 05/06/ 09 (colheita 2), 19/06/09 (colheita 3 ) e 03/07/09 (colheita 4), no cultivo outono/inverno e, em 18/12/09 (colheita 1), 29/12/09 (colheita 2) e em 06/01/10 (colheita 3 ), no cultivo primavera/verão. A variável usada foi a fitomassa fresca das vagens.

Para cada linha de cultivo em cada colheita e agrupamento de colheitas, estimou-se a média $(\bar{X})$, a variância $\left(\mathrm{s}^{2}\right)$ e o coeficiente de variação $(\mathrm{CV} \%)$. Para testar a heterogeneidade das variâncias entre as linhas de cultivos, aplicou-se o teste de Bartlett (STEEL et al., 1997) a 5\% de significância. Nos casos em que as variâncias das linhas não foram heterogêneas, calculouse também um CV\% representativo de todo o experimento e este foi usado na estimativa do tamanho da amostra. Nos casos em que as variâncias foram heterogêneas, utilizou-se o maior valor obtido de CV\% das linhas.

O cálculo do tamanho de amostra e a correção para população finita foram realizados pela metodologia proposta por COCHRAN (1977).

Pela expressão $\mathrm{n}=\frac{\mathrm{t}^{2} * \mathrm{CV}^{2} \%}{\mathrm{D}^{2} \%}$, na qual $n$ é o tamanho de amostra para população infinita, $t$ é o valor da tabela $t$ de Student com n-1 graus de liberdade e 5\% de probabilidade de erro tipo I, CV\% é o coeficiente de variação das fitomassas das vagens e D\% é a semiamplitude do intervalo de confiança da média $(\mathrm{D} \%=5$, 10,15 e 20), estimou-se o tamanho ideal de amostra para cada linha de cultivo. Como a população é finita, o tamanho final da amostra foi obtido pela fórmula $\mathrm{nc}=\frac{\mathrm{n}}{1+\frac{\mathrm{n}}{\mathrm{N}}}$,em que nc é o tamanho corrigido da amostra, N é o tamanho da população de cada linha de cultivo e n é o tamanho da amostra para população infinita.

As variáveis meteorológicas, brilho solar e temperatura média do ar, usadas para explicar as diferenças na variabilidade da produção das vagens, foram obtidas na Estação Climatológica Principal do $8^{-}$ Distrito de Meteorologia do Instituto Nacional de Meteorologia, localizada aproximadamente a $100 \mathrm{~m}$ da área experimental.

\section{RESULTADOS E DISCUSSÃO}

No cultivo do outono/inverno, na estufa plástica, foi constatada heterogeneidade das variâncias entre as linhas de cultivo em todas as colheitas e no túnel na metade (Tabela 1). Esse resultado mostra que estufas e túneis plásticos não geram um cultivo homogêneo, concordando com SOUZA et al. (2002), LORENTZ et al. (2005) e CARPES et al. (2008), que verificaram heterogeneidade de variâncias entre linhas em várias colheitas para outras culturas olerícolas nesses ambientes. Todos os experimentos apresentaram pelo menos uma colheita com variâncias heterogêneas entre as linhas de cultivo. No entanto, a análise da produção total, levou a variâncias não heterogêneas em todos os cultivos, exceto na estufa, indicando ser essa uma boa estratégia para diminuir a heterogeneidade das variâncias entre as linhas de cultivo, uma vez que o agrupamento das colheitas duas a duas não surtiu o mesmo efeito (Tabela 1).

Em todos os cultivos, para se obter uma diferença em porcentagem da média (D\%) de 10\%, ou seja, um intervalo de confiança para a média de $20 \%$ com 95\% de confiança, em todas as colheitas, agrupamentos de colheitas e para produção total, foi necessário um tamanho de amostra superior a 50\% da população de plantas na linha (Tabela 2). Esse tamanho de amostra relativamente alto indica alta variabilidade nessa cultura, que tem como uma das causas, as múltiplas colheitas e o ponto de colheita subjetivo. SOUZA et al. (2002) e LÚCIO et al. (2003) recomendaram, respectivamente, para abóbora italiana e pimentão, ambas de múltiplas colheitas e de ponto de colheita subjetivo, um tamanho de amostra também superior a $50 \%$ do número de plantas por linha de cultivo para obter um $\mathrm{D} \%=10$.

Nos experimentos das duas épocas, podese observar que a ocorrência de dias com poucas horas ( $\leq 3)$ de brilho solar ou com temperaturas adversas, a cultura, nos 10 dias anteriores as colheitas, levou a um aumento do coeficiente de variação $(\mathrm{CV} \%)$ na maioria das linhas de cultivo. Esses fatores ambientais também foram usados por SOUZA et al. (2002) e CARPES et al. (2008) para explicar diferenças na variabilidade da produção de abóbora italiana. Esses autores constataram que o número de dias com pouco ou nenhum brilho solar e/ou com temperaturas adversas influencia a variabilidade da produção de frutos da cultura que estudaram.

No outono/inverno, para o experimento realizado em estufa plástica, os maiores tamanhos de amostra foram na colheita 1 e 4 (Tabela 2), pois, nessas, em todas as linhas de cultivo, os coeficientes de variação (CV\%) foram maiores (Tabela 1). Os maiores CVs nessas colheitas podem ser explicados pela ocorrência de 4 dias com brilho solar inferior a 3 horas no período anterior a elas, visto que, nos dez dias 
Tabela 1 - Média $(\bar{X})$, em g, e coeficiente de variação (CV\%), em percentagem, da produção de fitomassa fresca de vagens de feijão-devagem, por linha de cultivo, para a produção, por colheita (C), por agrupamentos de colheitas e total, em duas épocas de cultivo em diferentes ambientes. Santa Maria-RS, 2010.

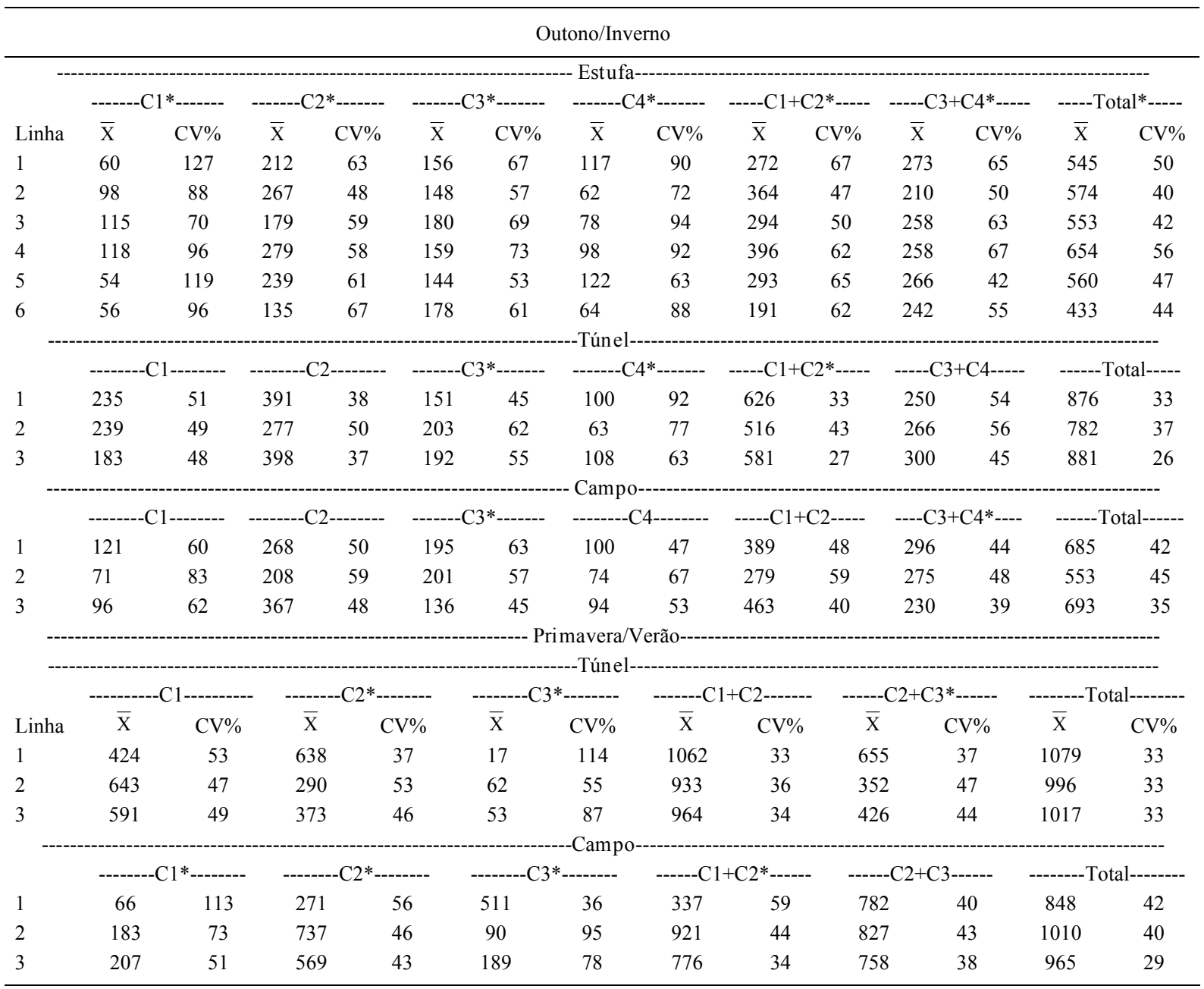

* Variâncias heterogêneas entre linhas de cultivo pelo teste de Bartlett a 5\% de probabilidade de erro.

anteriores às colheitas 2 e 3 , ocorreu um menor número de dias com essa condição, os quais foram, respectivamente, três e um dias (Figura 1A). Na colheita 3 , apesar de ter ocorrido somente um dia com a condição desfavorável citada anteriormente, o tamanho de amostra foi maior que na colheita 2 devido à ocorrência de um maior número de dias com temperaturas inferiores ao limite mínimo da faixa ideal para a cultura $\left(18^{\circ} \mathrm{C}\right)$ no período anterior a elas (Figura 1B), que levou a uma elevação dos valores do CV\%, na maioria das linhas de cultivo (Tabela 1).

$\mathrm{Na}$ colheita 3 do experimento realizado no túnel, no outono/inverno, o tamanho de amostra foi maior que nas colheitas 1 e 2, que tiveram, nos dez dias que as antecedeu, mais dias com brilho solar inferior a três horas. Isso ocorreu devido às temperaturas adversas já citadas e porque as variâncias entre as linhas de cultivo foram heterogêneas, sendo o cálculo do tamanho da amostra realizado utilizando-se o maior $\mathrm{CV} \%$ das linhas. Na colheita 1, elas não foram heterogêneas e, por isso, o cálculo foi feito utilizando o CV\% geral (Tabela 1). Pelo mesmo motivo, no experimento a campo dessa mesma época, os tamanhos de amostra na colheita 3 foram maiores que na colheita 4 .

Nos experimentos realizados na primaveraverão, o maior número de dias com brilho solar inferior a três horas ocorreram nos dez dias anteriores às colheitas 1 e 3 (Figura 1C). Isso explica os maiores tamanhos de amostra nessas colheitas, no cultivo a campo (Tabela 2). No cultivo no túnel, na colheita 2 , 
Tabela 2 - Tamanho de amostra em número de unidades básicas por linha de cultivo, para a fitomassa fresca, total, por colheita individual e agrupada, de vagens de feijão-de-vagem em duas épocas de cultivo, em diferentes ambientes, para diferentes semi-amplitudes do intervalo de confiança da média (D\%). Santa Maria-RS, 2010.

\begin{tabular}{|c|c|c|c|c|c|c|c|}
\hline \multicolumn{8}{|c|}{ Outono/Inverno } \\
\hline $\mathrm{D} \%$ & $\mathrm{C} 1$ & $\mathrm{C} 2$ & $\mathrm{C} 3$ & $\mathrm{C} 4$ & $\mathrm{C} 1+\mathrm{C} 2$ & $\mathrm{C} 3+\mathrm{C} 4$ & Total \\
\hline 5 & 35 & 34 & 34 & 35 & 34 & 34 & 34 \\
\hline 10 & 34 & 30 & 31 & 33 & 30 & 30 & 28 \\
\hline 15 & 32 & 25 & 26 & 29 & 25 & 25 & 22 \\
\hline 20 & 29 & 20 & 22 & 26 & 20 & 20 & 17 \\
\hline $\mathrm{D} \%$ & $\mathrm{C} 1$ & $\mathrm{C} 2$ & $\mathrm{C} 3$ & $\mathrm{C} 4$ & $\mathrm{C} 1+\mathrm{C} 2$ & $\mathrm{C} 3+\mathrm{C} 4$ & Total \\
\hline 5 & 38 & 37 & 39 & 41 & 37 & 38 & 33 \\
\hline 10 & 30 & 27 & 33 & 37 & 27 & 30 & 21 \\
\hline 15 & 22 & 19 & 26 & 33 & 19 & 22 & 14 \\
\hline 20 & 16 & 14 & 20 & 28 & 14 & 17 & 10 \\
\hline $\mathrm{D} \%$ & $\mathrm{C} 1$ & $\mathrm{C} 2$ & $\mathrm{C} 3$ & $\mathrm{C} 4$ & $\mathrm{C} 1+\mathrm{C} 2$ & $\mathrm{C} 3+\mathrm{C} 4$ & Total \\
\hline 5 & 40 & 39 & 39 & 39 & 38 & 38 & 36 \\
\hline 10 & 34 & 32 & 33 & 31 & 30 & 29 & 26 \\
\hline 15 & 28 & 24 & 26 & 24 & 22 & 21 & 18 \\
\hline 20 & 23 & 19 & 21 & 18 & 17 & 16 & 13 \\
\hline $\mathrm{D} \%$ & $\mathrm{C} 1$ & $\mathrm{C} 2$ & & & $\mathrm{C} 1+\mathrm{C} 2$ & $\mathrm{C} 2+\mathrm{C} 3$ & Total \\
\hline 5 & 38 & 38 & & & 34 & 37 & 34 \\
\hline 10 & 30 & 30 & & & 22 & 28 & 22 \\
\hline 15 & 23 & 23 & & & 15 & 20 & 14 \\
\hline 20 & 17 & 17 & & & 11 & 15 & 10 \\
\hline $\mathrm{D} \%$ & $\mathrm{C} 1$ & $\mathrm{C} 2$ & & & $\mathrm{C} 1+\mathrm{C} 2$ & $\mathrm{C} 2+\mathrm{C} 3$ & Total \\
\hline 5 & 41 & 39 & & & 39 & 36 & 35 \\
\hline 10 & 39 & 31 & & & 32 & 25 & 24 \\
\hline 15 & 35 & 24 & & & 25 & 18 & 16 \\
\hline 20 & 31 & 18 & & & 19 & 13 & 12 \\
\hline
\end{tabular}

apesar de menos dias com condições de brilho desfavorável antecedendo a esta colheita, o tamanho de amostra foi o mesmo que para a colheita 1 (Tabela 2). Isso ocorreu devido às temperaturas médias diárias terem sido maiores nos dias que antecederam a colheita 2 (Figura 1D). Devido ao efeito estufa promovido pela proteção ambiental, essas temperaturas podem ter alcançado o limite superior da faixa ideal da cultura $\left(30^{\circ} \mathrm{C}\right)$, aumentando a variabilidade. Além disso, na colheita 2, o CV\% usado no cálculo foi o da linha em que ele foi maior e, na colheita 1 , foi o geral do experimento. Por esse mesmo motivo, houve diferenças no tamanho de amostra nas colheitas 1 e 3 no túnel, em que houve um mesmo número de dias com brilho solar inferior a $3 \mathrm{~h}$ as antecedendo. Na colheita 3 , o cálculo foi realizado com o $\mathrm{CV} \%$ da linha em que ele foi maior e, no período anterior, as temperaturas foram mais próximas ao limite superior ideal que na colheita 1 (Figura 1D), por isso os tamanhos de amostra foram maiores (Tabela 2).

Nas duas épocas de cultivo, pode-se observar que o agrupamento da produção de todas as colheitas antes da análise possibilita a utilização de menores tamanhos de amostra que nas colheitas individuais ou agrupadas duas a duas (Tabela 2), pois possibilita uma diminuição dos valores de coeficiente de variação (CV\%) na maioria das linhas de cultivo. A redução dos CVs foi verificada em $83 \%$ das linhas de cultivo na estufa e, em $100 \%$ delas, no túnel e campo do outono/inverno. Nos cultivos da primavera/verão, o comportamento foi observado em $100 \%$ das linhas no túnel e em $67 \%$ das linhas no campo (Tabela 1). Isso 


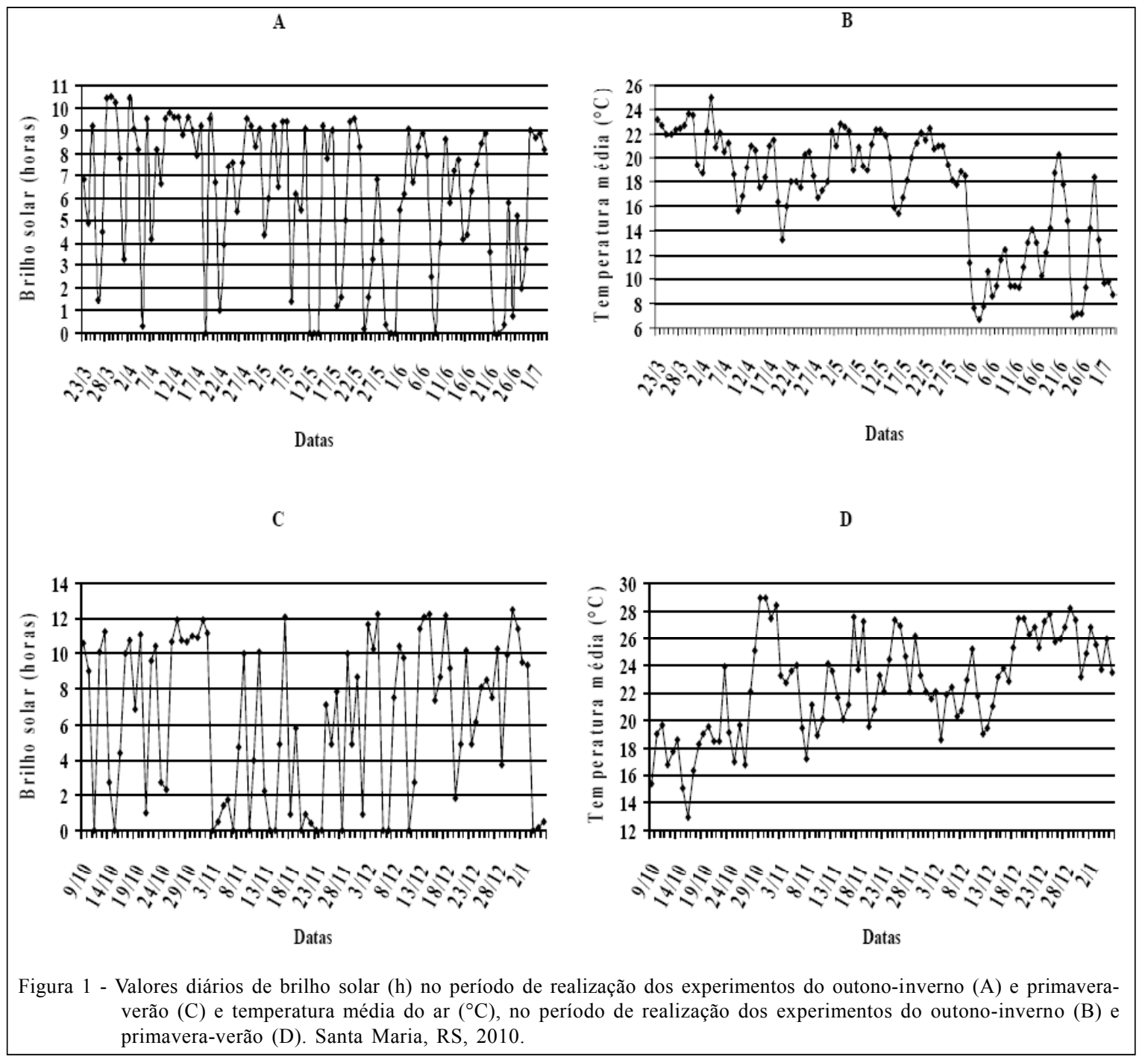

ocorre principalmente devido a alta sensibilidade dos CVs a alterações nas médias. Utilizando-se a produção total de vagens, as médias são mais elevadas que para as colheitas individuais ou agrupadas duas a duas e, dessa forma, os CVs são reduzidos, reduzindo também os tamanhos de amostra. As desvantagens de analisar a produção de vagens de maneira fracionada ao invés de total ficaram evidentes pelo esposto neste trabalho. Esses resultados são interessantes, pois se, futuramente, algum trabalho indicar alguma vantagem em avaliar a produção de vagens fracionadadente, ou que avaliar somente uma fração da produção de vagens já é suficiente para algum tipo de estudo, ou ainda, se algum estudo exigir informações mais detalhadas sobre a distribuição da produção durante o ciclo da cultura, já se sabe que haverá desvantagens na realização de amostragem e também que haverá uma maior heterogeneidade entre linhas de cultivo.

\section{CONCLUSÃO}

A variabilidade produtiva da vagem aumenta quando as condições de brilho solar e temperatura do ar são adversas, levando à necessidade de maiores tamanhos de amostra. Analisar a produção de vagens de todo o ciclo produtivo ao invés de analisar as colheitas individualmente, possibilita a utilização de menores tamanhos de amostra na cultura do feijãode-vagem.

Para uma semi-amplitude do intervalo de confiança da média (D\%) de 10, no outono/inverno, é necessário amostrar, na linha de cultivo, 28 plantas na estufa, 21 no túnel e 26 no campo. Na primavera/verão, 
para um $\mathrm{D} \%=10$, é necessário amostrar, na linha de cultivo, 22 plantas em cultivos em túnel e 24 a campo.

\section{AGRADECIMENTOS}

Ao Conselho Nacional de Desenvolvimento Científico e Tecnológico (CNPq) e à Fundação de Amparo à Pesquisa do Estado do Rio Grande do Sul (FAPERGS), pelo auxílio financeiro para a realização dos experimentos e bolsas de pesquisa e iniciação científica.

\section{REFERÊNCIAS}

ABREU, F.B. et al. Divergência genética entre acessos de feijãode-vagem de hábito de crescimento indeterminado. Horticultura Brasileira, Brasília, v.22, n.3, p.547-552, 2004. Disponível em: <http://www.scielo.br/pdf/hb/v22n3/a09v22n3.pdf>. Acesso em: 11 set. 2010. doi: 10.1590/S0102-05362004000300009.

CARPES, R.H. et al. Ausência de frutos colhidos e suas interferências na variabilidade da fitomassa de frutos de abobrinha italiana cultivada em diferentes sistemas de irrigação. Revista CERES, Viçosa, v.55, n.6, p.590-595, 2008. Disponível em: <http:// www.ceres.ufv.br/CERES/revistas/V55N006P37108.pdf>. Acesso em: 27 mar. 2009

COCHRAN, W.G. Sampling techniques. 3.ed. New York: John Willey, 1977. Cap.4, p.72-90.

EMBRAPA. Centro Nacional de Pesquisa de Solos (Rio de Janeiro, RJ). Sistema brasileiro de classificação dos solos. Brasília: Embrapa-SPI, 1999. 412p.

FERNANDES, E.N.; SILVA, P.S.L. Tamanho da amostra e método de amostragem para caracteres da espiga do milho. Ciência e Agrotecnologia, Lavras, v.20, n.2, p.252-256, 1996.

FILGUEIRA, F.A.R. Novo manual de olericultura: agrotecnologia moderna na produção e comercialização de hortaliças. Viçosa: UFV, 2000. 402p.

HELDWEIN, A.B. et al. Plastocrono e rendimento de feijãode-vagem cultivado sob ambiente protegido e no ambiente externo em semeadura tardia no outono. Ciência Rural, Santa Maria, v.40, n.4, p.768-773, 2010. Disponível em: $<$ http://www.scielo.br/pdf/cr/v40n4/a522cr2466.pdf $>$. Acesso em: 11 set. 2010 . doi: 10.1590/S0103-84782010005000045.
LORENTZ, L.H. et al. Variabilidade da produção de frutos de pimentão em estufa plástica. Ciência Rural, Santa Maria, v.35, n.2, p.316-323, 2005. Disponível em: <http://www.scielo.br/ s c i e lo.ph p s c ri p t $=$ s c i a r t text \& pid $=$ S 0103 $84782005000200011 \& \operatorname{lng}=\mathrm{pt} \& \mathrm{nrm}=\mathrm{iso} \& \operatorname{tng}=\mathrm{pt}>$. Acesso em: 27 mar. 2009. doi: 10.1590/S0103-84782005000200011.

LÚCIO, A.D. et al. Tamanho da amostra e método de amostragem para avaliação de características do pimentão em estufa plástica. Horticultura Brasileira, Brasília, v.21, n.2, p.180-184, 2003. Disponível em: <http://www.scielo.br/ s c i e lo.ph p s cript $=$ s ci_art text \& pid $=$ S 0102 $05362003000200012 \& \operatorname{lng}=$ en $\&$ nrm $=$ iso $\&$ tlng $=\mathrm{pt}>$. Acesso em: 14 mar. 2009. doi: 10.1590/S0102-05362003000200012.

MALUF, W.R. et al. A cultura do feijão de vagem. Lavras: Departamento de Agricultura, 2002. (Boletim Técnico de Hortaliças n.65). Disponível em: <http://www2.ufla.br/ $\sim$ wrmaluf/bth065/bth065.html>. Acesso em: 08 nov. 2009.

MARODIN, V.S. et al. Delineamento experimental e tamanho de amostra para alface cultivada em hidroponia. Ciência Rural, Santa Maria, v.30, n.5, p.779-781, 2000. Disponível em: <http:/ /www.scielo.br/scielo.php?script $=$ sci_arttext\&pid $=$ S0103$84782000000500006 \& \operatorname{lng}=\mathrm{pt} \& \mathrm{nrm}=\mathrm{iso} \& \mathrm{t} \operatorname{lng}=\mathrm{pt}>$. Acesso em: 14 mar. 2009. doi: 10.1590/S0103-84782000000500006.

MORENO, J.A. Clima no Rio Grande do Sul. Porto Alegre: Secretaria da Agricultura, 1961. 41p.

MUNIZ, J.A.; ABREU, A.R. Técnicas de amostragem. Lavras: UFLA/FAEPE, 1999. 102p.

SANTOS, P.M. et al. Cronograma de amostragem de plantas de alface hidropônica para ajuste de curvas de crescimento. Ciencia Rural, Santa Maria, v.37, n.6, p.1601-1608, 2007. Disponível em: <http:/ /www.scielo.br/scielo.php?script $=$ sci_arttext\&pid $=\mathrm{S} 0100$ 54052008000100021\&lng=en\&nrm=iso\&tlng=pt $>$. Acesso em: 26 mar. 2009. doi: 10.1590/S0103-84782007000600015.

SOUZA, M.F. et al. Tamanho da amostra para peso da massa de frutos, na cultura da abóbora italiana em estufa plástica. Revista Brasileira de Agrociência, Pelotas, v.8, n.2, p.123-128, 2002. Disponível em: <http://www.ufpel.tche.br/faem/agrociencia/ v8n2/artigo07.pdf>. Acesso em: 14 maio, 2009.

STEEL, R.G.D. et al. Principles and procedures of statistics abiometrical approach. 3.ed. Nova York: McGraw-Hill, 1997. 666p. 